\title{
CARDIOVASCULAR AND HORMONAL DISORDERS AMONG WORKERS OCCUPATIONALLY-EXPOSED TO NOISE
}

\author{
By
}

Khalifa EM and Shehata RA

Department of Occupational and Environmental Medicine Faculty of Medicine, Cairo University

Corresponding author: Shehata RA: rehab.shehata@kasralainy.edu.eg

\section{Abstract}

Introduction: Noise exposure is a common risk factor for many health adverse effects like hearing impairment, cardiovascular diseases and psychosocial dysfunction. Hypercholesterolemia is suspected to be the main factor for the pathogenesis of prolonged noise-associated cardiovascular extra-auditory effects of occupationally-induced noise. Occupational stress and noise exposure were associated with lowering of total and free testosterone in active male workers which in turn was considered as a risk factor for cardiovascular disease, obesity and many other diseases causing overall mortality. Aim of work: To evaluate the environmental measurement of occupational noise intensity at different units of concrete pipes industry and to assess the effect of occupational noise exposure (either auditory or extra-auditory) on the exposed workers with emphasis on cardiovascular symptoms, serum cholesterol and testosterone levels. Materials and methods: A comparative cross sectional is conducted upon 105 male workers in a company for reinforced concrete pipes at Cairo, Egypt. The study group ages ranged from 24- 60 years. Duration of work ranged from 2- 40 years. The workers are classified into two groups: group (A): 52 workers who are exposed to high level noise $\geq 85 \mathrm{~dB}$, and group (B): 53 workers who are exposed to low level noise $<85 \mathrm{~dB}$. Both groups were interviewed using specially designed questionnaire with emphasis on occupational history ,cardiac history ,history of hearing impairment and sleep disturbances .Clinical (general and systemic) examination was done. Laboratory investigations were performed including serum total cholesterol level, total and free serum testosterone levels. Results: The prevalence of hearing impairment was significantly higher among workers exposed to noise level above $85 \mathrm{dBA}(61.5 \%)$ as well as the prevalence of cardiac symptoms as palpitation, ischemic heart diseases and history of catheterization were significantly higher among workers from group (A) $(53.8 \%, 40.4 \%$ and $15.4 \%$ respectively). The levels of total serum cholesterol were significantly higher among workers exposed to noise levels above $85 \mathrm{dBA}$ (odds Ratio $=17.6$ ) while total and free testosterone were significantly lower among the same group. Conclusion: The current study revealed that exposure to chronic occupational noise above $85 \mathrm{dBA}$ was associated with hypercholesterolemia that leads in turn to cardiovascular disorders and also associated with low levels of serum testosterone hormone.

Key words: Occupational noise, Serum cholesterol, Serum testosterone and cardiovascular disorders. 


\section{Introduction}

Exposure to noise is a common risk factor for many health adverse effects like hearing impairment, cardiovascular diseases, psychosocial dysfunction, cognitive impairment, and adverse pregnancy outcomes (Basneret al., 2014).

Occupations with the highest prevalence of noise exposure were production (55\%); construction and extraction (54\%); and installation, maintenance and repair $(54 \%)(\mathrm{NIOSH}$, 2018).

Noise-induced hearing loss (NIHL) is one of the most common occupational disorders among industrialized populations; it is associated with longstanding exposure to high levels of noise. The pathogenesis of NIHL is not clear and it could be due to several factors; genetic predisposition and microcirculation disturbance are suspected to be important factors in the pathogenesis of NIHL. Hypercholesterolemia with prolonged exposure to noise, which can disturb the microcirculation, can be one of the underlying pathologies in hearing loss and can lead to cardiovascular extraauditory effects of noise (Mehmetand Sedat, 2018).

Chronic exposure to noise can cause imbalance in the homoeostasis, with increases in established cardiovascular disease risk factors such as blood pressure, blood lipid concentrations, blood viscosity, and blood glucose concentrations. These changes increase the risk of hypertension, arteriosclerosis and are related to severe events, such as myocardial infarction and stroke (Babisch, 2011).

Many investigators have noted that noise exposure increases systolic and diastolic blood pressures, changes heart rate, and causes the release of stress hormones (including catecholamines and glucocorticoids) (Lusk et al., 2004).

Studies of occupational and environmental epidemiology have shown a higher prevalence and incidence of cardiovascular diseases and mortality in highly noise-exposed groups. The risk estimates for occupational noise at ear-damaging intensities tend to be higher than are those for environmental noise (at lower noise levels) (Davies et al., 2012).

A study was done by Kerns and his colleagues (2018) provides evidence that there is an association of occupational noise exposure with high blood pressure and high cholesterol levels; they also concluded that workplace-based health and wellness programs should be considered as preventive measures to reduce these risk factors. 
Testosterone is a vital hormone for male sexual maturation and development, for cognitive performance, psychosocial functioning, body composition, and metabolic control (Seftel, 2006). The hypothalamic-pituitary-testicular (HPT) axis is sensitive to gonadotropic hypogonadism. Occupational and environmental noise act as stressors and stimulate the HPA (Hypothalamicpitutary-axis), and have been implicated as a risk factor for testosterone deficiency (Dzhambov et al., 2015)

Occupational noise exposure was associated with significantly lower total and free testosterone in active male workers aged 16-85+ years in the US general population (Dzhambov, 2016).

Low testosterone is a risk factor for cardiovascular disease, obesity, diabetes, bone mineral density loss, depression, impaired cognitive and social functioning, and overall mortality (Zarotsky et al., 2014).

\section{Aim of work}

To evaluate the environmental measurement of occupational noise intensity at different units of concrete pipes industry and to assess the effect of occupational noise exposure (either auditory or extra-auditory) on the exposed workers with emphasis on cardiovascular symptoms, serum cholesterol and testosterone levels.

\section{Materials and methods}

Study design: It is a comparative crosssectional study.

Place and duration of the study: the study was conducted in a company for reinforced concrete pipes and cement products at Cairo, Egypt, from June to September 2017.

Study sample: The ages of the study group ranged from 24- 60 years. Duration of employment ranged from 2- 40 years. The workers were classified into two groups: Group (A): 52 workers who were exposed to high level noise $<85 \mathrm{dBA}$, and group (B): 53 workers who were exposed to low-level noise $\leq$ $85 \mathrm{dBA}$. This classification is according to the permissible exposure limit (PEL) of the National Institute for Occupational Safety and Health (NIOSH, 1998) and American Conference of Governmental Industrial Hygienists (ACGIH, 2006a). The PEL of the Egyptian law is mentioned as a part of information and data regarding our country law but it is not used as a reference for classification in the study.

Study methods: Both groups were subjected to the following:

\section{1- Predesigned questionnaire} including: personal history (age, gender, marital status, number of children, smoking habits and medical history), occupational history (duration of employment 
and working hours, working department, leisure time and previous job) and cardiac history (hypertension, ischemic heart disease, catheterization, exertional dyspnea and palpitation). History of reproductive health problems or previous investigations was asked to exclude any reproductive disorders.

2- Diagnosis of hearing impairment among the studied workers was depending on the history of previous diagnosis of hearing disability by Health Insurance Compensation Committee and the use of a hearing aid.

3- Sleep apnea was diagnosed according to the International Classification of Sleep Disorders by the American Academy of Sleep Medicine (2005). Diagnosis was depending on at least 1 of the following criteria: Sleep disturbance in the form of daytime sleepiness, insomnia, unintentional sleep episodes during wakefulness as well as witnessed snoring and breathing interruptions or awakenings due to gasping or choking.

4- Full clinical examination was performed.

\section{5- Laboratory investigations:}

A sample of $7 \mathrm{ml}$ of venous blood was withdrawn from every subject in the morning. The blood is collected in a tube with no anticoagulant and left to clot at room temperature for 30 minutes then centrifuged for 20 minutes, after that the sample was stored at $-80^{\circ} \mathrm{c}$ prior to the assay.

The sample was divided into three smaller samples to suit the different laboratory measurements.

- Total cholesterol: Cholesterol kits which are simple calorimetric assay were used to measure total cholesterol amount in serum in a sample of $3 \mathrm{ml}$ of venous blood. The assay measures total cholesterol (cholesteryl esters and free cholesterol) in the presence of cholesterol esterase. It is analyzed enzymatically by Roche Cobas 6000 chemistry analyzer.

- Total testosterone (TT): A sample of $2 \mathrm{ml}$ venous blood was analyzed by the use of immunoassay analyzer Cobas e 411. It is a second generation platform of Electrochemiluminescence (ECL) technology.

- $\quad$ Free testosterone (FT): A sample of $2 \mathrm{ml}$ venous blood was measured by radioimmunoassay test kits. Reagents are added to the blood sample. Testosterone antibodies with radioactive particles in the reagent bind to testosterone in the sample and the level is detected by counting the number of testosterone molecules bound to the antibodies. 


\section{6- Environmental measurements}

of noise were done using Digital Sound Level Meter model 732 giving direct measurements in decibel with $30-130 \mathrm{~dB}$ capability in three measurement ranges low, medium and high. It includes frequency weighting $\mathrm{A}$ and $\mathrm{C}$ and fast and slow time weighting (NOISH, 1998).

Environmental measurements of noise were performed only once in a single visit at different places and during many steps of the industrial process and results were as follows: Preparation and storage of raw material: $80 \mathrm{dBA}$, Mixing of concrete: 91dBA, Preparing steel reinforcement cage of concrete pipes: $89 \mathrm{dBA}$, Molding: $74 \mathrm{dBA}$, Remolding: 76dBA, Finishing and hammering: 92dBA.

\section{Consent}

Verbal consent was taken from all the workers who participated in the study and consent was taken from the management of the factory where the study was carried out and confidentiality was maintained.

\section{Ethical approval}

The study procedures were approved by the Occupational and Environmental Medicine Department Ethical Committee, Faculty of Medicine, Cairo University.

\section{Data management}

Data were coded and entered using the statistical package SPSS version 25. Data were presented using mean, standard deviation, median, minimum and maximum for quantitative variables and frequencies (number of cases) and relative frequencies (percentages) for categorical variables. Comparisons between groups were done using unpaired $t$ test in normally distributed quantitative variables while non-parametric Mann-Whitney test was used for non-normally distributed quantitative variables (Chan, 2003a). For comparing categorical data, Chi square (c2) test was performed. Exact test was used instead when the expected frequency was less than 5 (Chan, 2003b). Correlations between quantitative variables were done using Spearman correlation coefficient (Chan, 2003c). Logistic regression was done to detect if high noise level acts as independent predictor of different outcomes (Chan, 2004). P-values less than 0.05 were considered as statistically significant. 


\section{Results}

Table (1): Socio-demographic and occupational characteristics of the studied groups.

\begin{tabular}{|c|c|c|c|c|c|c|c|}
\hline & & \multicolumn{4}{|c|}{ Groups } & & \\
\hline & \multicolumn{2}{|c|}{$\begin{array}{c}\text { Group A } \\
\text { noise level } \\
>85 \text { dBA } \\
\text { No: } 52\end{array}$} & \multicolumn{2}{|c|}{$\begin{array}{c}\text { Group B } \\
\text { noise level } \\
\leq \mathbf{8 5 d B A} \\
\text { No: } 53\end{array}$} & & & \\
\hline & Mean & SD & Mean & SD & $\begin{array}{c}\text { Tests of } \\
\text { significance }\end{array}$ & $\begin{array}{c}\mathbf{p} \\
\text { value }\end{array}$ & \\
\hline \multicolumn{2}{|l|}{ Age (years) } & 52.90 & 6.80 & 50.68 & 7.68 & $\begin{array}{l}-1.570 \\
(\mathrm{t}-\text { test })\end{array}$ & 0.119 \\
\hline \multicolumn{2}{|l|}{ Smoking index } & 149.13 & 287.30 & 153.96 & 197.93 & $\begin{array}{c}1.242 \\
(\mathrm{z} \\
\text { score })\end{array}$ & 0.214 \\
\hline \multicolumn{2}{|c|}{ Number of children } & 3.56 & 1.79 & 3.21 & 1.35 & $\begin{array}{c}-0.808 \\
(\mathrm{z} \\
\text { score })\end{array}$ & 0.419 \\
\hline \multicolumn{2}{|c|}{$\begin{array}{l}\text { Duration of employment } \\
\text { (years) }\end{array}$} & 25.04 & 9.43 & 22.17 & 6.24 & $\begin{array}{c}-2.349 \\
(\mathrm{z} \\
\text { score })\end{array}$ & $0.019 *$ \\
\hline \multirow{2}{*}{ Marital status } & Unmarried & 0 & $0.0 \%$ & 3 & $5.7 \%$ & \multirow{2}{*}{$\begin{array}{r}3.030 \\
\left(\chi^{2)}\right)\end{array}$} & \multirow{2}{*}{0.243} \\
\hline & Married & 52 & $100.0 \%$ & 50 & $94.3 \%$ & & \\
\hline
\end{tabular}

*: Statistically significant

$\chi^{2}$ : chi square

Table (1) shows mean values and standard deviations (SD) and frequency distribution of demographic and occupational characteristics elicited among the two studied groups. There are statistically significant differences between the two groups concerning duration of employment $(<0.05)$, while there is no statistically significant difference between the two groups as regards age, smoking index, number of children and marital status $(>0.05)$. 


\section{Table (2): Frequency distribution of auditory and extra-auditory} manifestations among the studied groups according to the medical history.

\begin{tabular}{|c|c|c|c|c|c|c|c|}
\hline $\begin{array}{l}\text { Auditory and } \\
\text { extra-auditory }\end{array}$ & & \multicolumn{4}{|c|}{ Groups } & \multirow{3}{*}{$\begin{array}{l}\text { Chi } \\
\text { square }\end{array}$} & \multirow{3}{*}{$p$ value } \\
\hline & \multicolumn{2}{|c|}{$\begin{array}{c}\text { Group A } \\
\text { noise level } \\
>85 \text { dBA } \\
\text { No: } 52\end{array}$} & \multicolumn{2}{|c|}{$\begin{array}{c}\text { Group B } \\
\text { noise level } \\
\leq 85 \mathrm{dBA} \\
\text { No: } 53\end{array}$} & & & \\
\hline & Count & $\%$ & Count & $\%$ & & & \\
\hline \multirow{2}{*}{$\begin{array}{c}\text { Hearing } \\
\text { impairment }\end{array}$} & Yes & 32 & $61.5 \%$ & 0 & $0.0 \%$ & \multirow[t]{2}{*}{46.913} & \multirow{2}{*}{$<0.001 * *$} \\
\hline & NO & 20 & $38.5 \%$ & 53 & $100.0 \%$ & & \\
\hline \multirow{2}{*}{$\begin{array}{l}\text { Presence of } \\
\text { hypertension } \\
\text { (HTN) }\end{array}$} & Yes & 27 & $51.9 \%$ & 18 & $34.0 \%$ & \multirow[t]{2}{*}{3.457} & \multirow{2}{*}{0.063} \\
\hline & NO & 25 & $48.1 \%$ & 35 & $66.0 \%$ & & \\
\hline \multirow{2}{*}{$\begin{array}{l}\text { History of } \\
\text { palpitation }\end{array}$} & Yes & 28 & $53.8 \%$ & 8 & $15.1 \%$ & \multirow[t]{2}{*}{17.494} & \multirow{2}{*}{$<0.001 * *$} \\
\hline & NO & 24 & $46.2 \%$ & 45 & $84.9 \%$ & & \\
\hline \multirow{2}{*}{$\begin{array}{l}\text { History of ischemic } \\
\text { heart disease (IHD) }\end{array}$} & Yes & 21 & $40.4 \%$ & 3 & $5.7 \%$ & \multirow[t]{2}{*}{17.949} & \multirow{2}{*}{$<0.001 * *$} \\
\hline & NO & 31 & $59.6 \%$ & 50 & $94.3 \%$ & & \\
\hline \multirow{2}{*}{$\begin{array}{c}\text { History of } \\
\text { catheterization }\end{array}$} & Yes & 8 & $15.4 \%$ & 0 & $0.0 \%$ & \multirow[t]{2}{*}{8.826} & \multirow{2}{*}{$0.003 *$} \\
\hline & NO & 44 & $84.6 \%$ & 53 & $100.0 \%$ & & \\
\hline \multirow{2}{*}{ Exertional dyspnea } & Yes & 29 & $55.8 \%$ & 8 & $15.1 \%$ & \multirow[t]{2}{*}{19.029} & \multirow{2}{*}{$<0.001 * *$} \\
\hline & $\mathrm{NO}$ & 23 & $44.2 \%$ & 45 & $84.9 \%$ & & \\
\hline \multirow{2}{*}{ Sleep apnea } & Yes & 20 & $38.5 \%$ & 0 & $0.0 \%$ & \multirow[t]{2}{*}{25.181} & \multirow{2}{*}{$<0.001 * *$} \\
\hline & NO & 32 & $61.5 \%$ & 53 & $100.0 \%$ & & \\
\hline
\end{tabular}

*: Statistically significant

**: Highly statistically significant

HTN: Hypertension

IHD: Ischemic heart disease

Table (2) shows statistically significant differences between the two groups as regard the prevalence of all auditory and extra auditory manifestations with highly statistical increase in percentage of hearing impairment, history of cardiac symptoms ,occurrence of dyspnea and sleep apnea among group A. 
Table (3): Mean values and SDs of blood pressure and lab measurements and frequency distribution of total cholesterol, total and free testosterone among the studied groups.

\begin{tabular}{|c|c|c|c|c|c|c|}
\hline & \multicolumn{4}{|c|}{ Groups } & \multirow[b]{3}{*}{$\begin{array}{c}\text { Tests of } \\
\text { significance }\end{array}$} & \multirow[b]{3}{*}{ p value } \\
\hline & \multicolumn{2}{|c|}{$\begin{array}{c}\text { Group A } \\
\text { noise level } \\
>85 \text { dBA } \\
\text { No:52 }\end{array}$} & \multicolumn{2}{|c|}{$\begin{array}{c}\text { Group B } \\
\text { noise level } \\
\leq \text { 85dBA } \\
\text { No:53 }\end{array}$} & & \\
\hline & Mean & SD & Mean & SD & & \\
\hline $\begin{array}{l}\text { Systolic blood } \\
\text { pressure }\end{array}$ & 140.00 & 21.96 & 131.32 & 18.81 & $-2.176(\mathrm{t}-\mathrm{test})$ & $0.032 *$ \\
\hline $\begin{array}{c}\text { Diastolic blood } \\
\text { pressure }\end{array}$ & 85.00 & 12.99 & 80.57 & 11.17 & $-1.877(\mathrm{t}-$ test $)$ & 0.063 \\
\hline $\begin{array}{l}\text { Total cholesterol } \\
\text { (TC) }\end{array}$ & 210.00 & 39.27 & 149.81 & 38.32 & $-7.949(\mathrm{t}-$ test $)$ & ( $001 \%$ \\
\hline High TC & $\begin{array}{c}\text { Count } \\
36\end{array}$ & $\begin{array}{c}\% \\
69.2 \% \\
\end{array}$ & $\begin{array}{c}\text { Count } \\
6 \\
\end{array}$ & $\begin{array}{c}\% \\
11.3 \% \\
\end{array}$ & & $<0.001$ \\
\hline $\begin{array}{c}\text { Total testosterone } \\
\text { (TT) }\end{array}$ & 3.96 & 1.79 & 5.34 & 1.67 & 3.555 (z score) & $<0.001 * *$ \\
\hline Low TT & 15 & $28.8 \%$ & 0 & $0.0 \%$ & & \\
\hline $\begin{array}{c}\text { Free testosterone } \\
(\text { FT) }\end{array}$ & 9.82 & 3.45 & 15.20 & 6.12 & 4.583(z score) & $<0.001 * *$ \\
\hline Low FT & 15 & $28.8 \%$ & 0 & $0.0 \%$ & & \\
\hline
\end{tabular}

*: Statistically significant

**: Highly statistically significant.

Total cholesterol : $(\mathrm{N}=<200 \mathrm{mg} / \mathrm{dl})$, Total testosterone ( $\mathrm{N}:<50$ years: $2.5-8.4 \mu \mathrm{g} / \mathrm{dl}, \geq 50$ years: 1.9$7.4 \mu \mathrm{g} / \mathrm{dl})$, Free testosterone (N: 9-40 $\mu \mathrm{g} / \mathrm{dl})$.

Table (3) shows that mean values and standard deviations (SD) of systolic blood pressure, and total cholesterol are higher among group exposed to high noise level (group A), while total testosterone and free testosterone in group A are lower compared to the group B (exposed to low noise level) and the differences are statistically significant. As regard diastolic blood pressure, there is no statistically significant difference between the two groups. 
Table (4): Correlation between duration of exposure and multiple clinical and laboratory measurements of the studied groups.

\begin{tabular}{|l|c|c|c|c|c|c|c|c|c|c|}
\hline & \multicolumn{2}{|c|}{$\begin{array}{c}\text { Systolic } \\
\text { BP }\end{array}$} & \multicolumn{2}{c|}{$\begin{array}{c}\text { Diastolic } \\
\text { BP }\end{array}$} & \multicolumn{2}{|c|}{ Total cholesterol } & \multicolumn{2}{c|}{$\begin{array}{c}\text { Total } \\
\text { testosterone }\end{array}$} & \multicolumn{2}{c|}{$\begin{array}{c}\text { Free } \\
\text { testosterone }\end{array}$} \\
\cline { 2 - 11 } $\begin{array}{l}\text { Duration of } \\
\text { exposure to } \\
\text { Noise/years }\end{array}$ & $\mathbf{R}$ & $\mathbf{p}$ - value & $\mathbf{R}$ & $\mathbf{p}$-value & $\mathbf{R}$ & $\mathbf{p}$ - value & $\mathbf{R}$ & $\mathbf{p}$ - value & $\mathbf{R}$ & $\mathbf{p}$ - value \\
\cline { 2 - 11 } & 0.323 & $\mathbf{0 . 0 0 1} * *$ & 0.211 & $\mathbf{0 . 0 3 1}$ & 0.456 & $<\mathbf{0 . 0 0 1} * *$ & -0.339 & $<\mathbf{0 . 0 0 1} * *-0.297$ & $\mathbf{0 . 0 0 2} * *$ \\
\hline
\end{tabular}

*: Statistically significant $\quad * *$ : Highly statistically significant.

R: correlation coefficient

Table (4) shows statistically significant positive correlation between duration of exposure as an occupational parameter and both of systolic, diastolic blood pressure measurement and the level of total cholesterol. There is significant negative correlation between duration of employment and both of total and free testosterone levels.

Table (5): Logistic regression analysis to detect significance of high noise level as independent predictor of different outcomes among the studied groups.

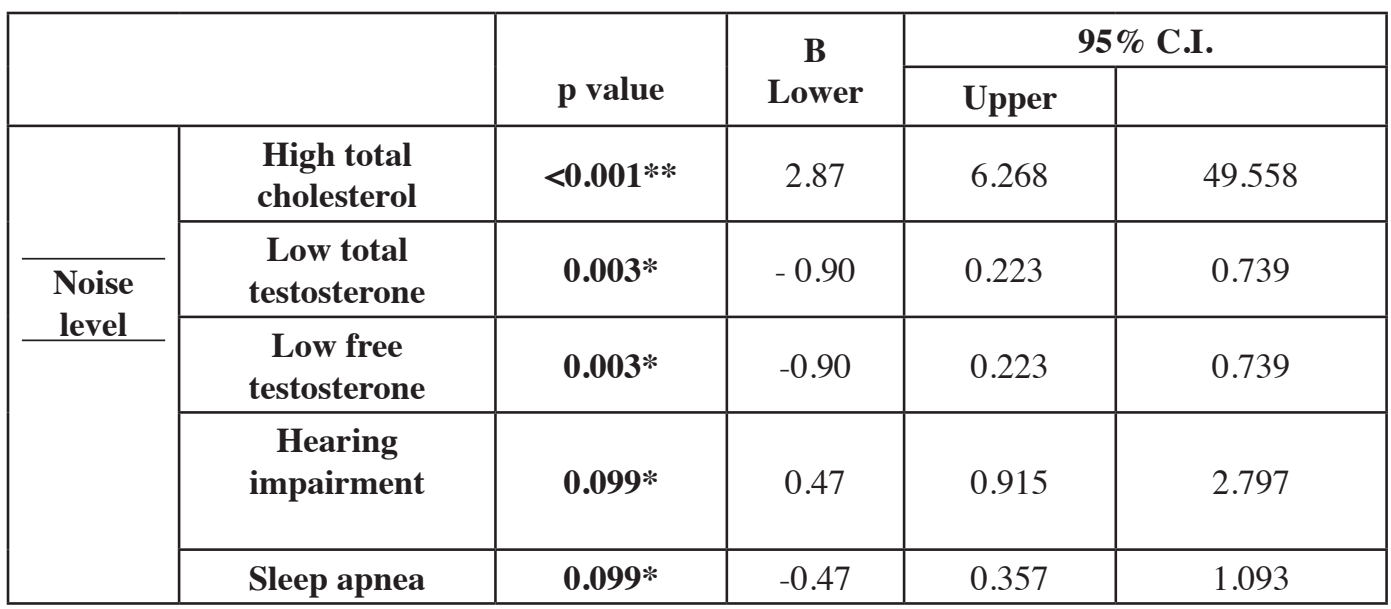

*: Statistically significant $\quad * *$ : Highly statistically significant. B: The regression coefficient

Table (5) reveals that high noise level acts as a significant independent predictor of clinical manifestations such as hearing impairment and sleep apnea. High noise level is also a significant independent predictor of high cholesterol level and low total and free testosterone levels among the studied groups. Odds ratio (OR) of cholesterol equals 17.625 and no odds ratio of other parameters as there's some cells with zero frequency. 


\section{Discussion}

Many industrial processes and work activities are associated with production of high noise levels; the most common sources are the use of heavy machines, production lines, electric tools and the impact processes (WHO, 2004). In this study, environmental measurement revealed that noise was generated during several process of production of concrete pipes, the noise measurement ranged from 74 -92dBA.

The lowest measurement was74 $\mathrm{dBA}$ in molding and during remolding steps was $76 \mathrm{dBA}$ followed by $80 \mathrm{dBA}$ at preparation and storage of raw materials. All these measurements are within the permissible exposure limits (PEL), while measurement at the area of preparing steel reinforcement cage of concrete pipes was $89 \mathrm{dBA}$, mixing of concrete was $91 \mathrm{dBA}$ and the highest measurement was $92 \mathrm{dBA}$ at the finishing department and during hammering. All these measurements are higher than the permissible exposure limits (PEL) according to Occupational Safety and Health Administration (OSHA) and the American Conference of Governmental Industrial Hygienists (ACGIH, 2006 a) the limit is 85 decibel $(85 \mathrm{dBA}$ as an 8=hr TWA).
In the current study, the workers were subdivided into two groups according to the level of noise intensity as measured environmentally at the workplace. Group A included workers who were occupationally exposed to level of noise more than $85 \mathrm{dBA}$, and group B included workers who were exposed to levels noise equal to or less than $85 \mathrm{dBA}$.

All workers worked 8 hours per day for 5 days per week and they were working in a morning shifts. On comparing the mean age, smoking index and number of children among the two studied groups; a non-significant statistical difference between the two groups was present, and so both groups were matched as regards age, smoking habit and number of children (Table 1). As regards duration of employment, there was statistically significant difference between the two groups; the group of workers exposed to high noise level was shown to have longer duration of exposure than the group of workers exposed to low noise level with mean values of $25.04 \pm 9.43$ and $22.17 \pm 6.24$, respectively. As regards marital status, all of group A were married (100\%), while the vast majority of group B (94.3\%) were married with no statistically significant difference between the two groups, as shown in (Table1). 
The majority of workers in group A (32 subjects, $61.5 \%)$ suffered from hearing impairment compared to no cases $(0 \%)$ among group $\mathrm{B}$ as shown in (Table 2).

The results of the present study are consistent with those of Nada et al. (2014), who found high prevalence of noise induced hearing loss NIHL in 107 out of $145(73.8 \%)$ workers in textile industry who were exposed to noise intensity exceeding $90 \mathrm{~dB}$.

In another case-control study conducted by Bhumika et al.(2013), among shipyard workers in India who were exposed to noise $>90 \mathrm{dBA}$ daily, they found that only $6 \%$ of workers developed NIHL. These results are much lower than the results of the current study which may be explained by the variance in the noise intensity which exceeded $90 \mathrm{dBA}$ at certain places where hammering, riveting and cutting took place, while it ranged from 70-80 dBA at other places where generators and blowers were used. The average noise level was $65 \mathrm{dBA}$.

These results were in accordance with the findings of Rabinowitz and Rees (2005), who found that Indian workers exposed to sound levels of 85 $\mathrm{dBA}$ and above for duration of $8 \mathrm{~h}$ per day experienced hearing damage after many years.
Twenty workers (38.5\%) in group A complained from sleep apnea compared to no similar complaint among the other group as shown in (Table 2).

In resemblance to the current work, the study done by Test et al. (2011) on the influence of hearing impairment on sleep quality among workers exposed to harmful noise; they found that workers occupationally exposed to high noise contributed to sleep impairment, especially to insomnia.

However, contrary to these current results, a study by Bonet-Porqueras (2009) concluded that the connection between industrial noise and sleeping disturbance is ambiguous, due to the difficulty in isolating noise as the only source for stress.

The present study showed that cardiovascular symptoms expressed by workers as hypertension, history of ischemic heart disease, history of catheterization, exertional dyspnea and palpitation were more prevalent among workers in group A compared to group B (Table 2).

Workers in group A gave history of catheterization among 8 (15.4\%) of workers compared to no similar complaint among group B workers, $21(40.4 \%)$ of workers in group A gave history of ischemic heart disease 
compared to only $3(5.7 \%)$ of workers in group B. More than half of workers in group A suffered from exertional dyspnea, palpitation and hypertension in $29(55.8 \%), 28(53.8 \%)$ and $27(51.9 \%)$, respectively compared to $8(15.1 \%)$, $8(15.1 \%)$ and $18(34 \%)$, respectively in group B. There is a statistically significant difference between the two groups as regards all symptoms ( $\mathrm{p}<$ 0.05 ) except for hypertension, as shown in (Table 2).

The findings of the present study were in agreement with the finding of Gopinath et al. (2011), who found that workers in noisy workplaces without hearing protectors were $53 \%$ and $75 \%$ more likely to have prevalent CVD and angina respectively.

Van Kempen et al. (2002) reported that every $5 \mathrm{~dB}$ increase in occupational noise intensity represent an estimated risk of hypertension.

Tomei et al.( 2010) found that workers exposed to high noise (92.2 \pm 6.5dBA) had significantly higher prevalence of hypertension, palpitation and electrocardiogram abnormalities.

However, contrary to the present study, Stokholm et al. (2013) reported no association between elevated hypertension and occupational noise exposure in the range of 80-90 dBA. Also, Gan et al. (2011) found that the relationship between occupational noise exposure and cardiovascular disease remains unsettled.

The current study showed that total blood cholesterol levels as well as values of systolic blood pressure were statistically significantly higher among workers exposed to noise level $>85 \mathrm{~dB}$ than those exposed to lower level of noise $(\leq 85 \mathrm{~dB})$; as regards diastolic blood pressure there was a slight increase in the mean value of about $5 \mathrm{~mm} \mathrm{Hg}$ among workers exposed to higher noise level (85) but the difference did not reach the level of significance. It also showed that the levels of serum total cholesterol were higher among group A in 36 workers $(69.2 \%)$ compared to group B in which there were only 6 workers $(11.3 \%)$ with higher levels, and the differences were statistically significant $(\mathrm{p}<0.05)$ (Table 3).

Similarly, Krens and his colleagues (2018) in their study showed that 58\% of workers had hearing difficulty, $14 \%$ of them reported hypertension, and $9 \%$ of workers had elevated cholesterol levels; these results were attributed to occupational noise exposure above 85 dBA. 
Hypertension and high serum cholesterol are more common among workers exposed to loud noise at work; according to a recent study conducted by the CDC's and National Institute for Occupational Safety and Health (NIOSH, 2018). Occupational noise exposure contributed to 58 percent of hearing difficulty cases, 14 percent of hypertension cases and 9 percent of elevated cholesterol cases.

In a study done on different units of an automotive parts manufacturing industry in Tehran; the results of paired t-test indicated that there was a significant difference between heart rate and diastolic blood pressure of all workers in the study and control groups after noise exposure compared to the values before exposure $(\mathrm{P}<0.050)$, but there were an increase in systolic blood pressure of workers just in the study group after noise exposure. No increase was detected in systolic blood pressure among workers in the control group (Saba et al., 2015).

On the other hand, Tarter and Robins (1990) who studied the relationship between chronic noise exposure and hypertension among150 automotive assembly workers regarding measured blood pressure levels; found that among the studied workers, average diastolic blood pressure was higher than 90 $\mathrm{mm} \mathrm{Hg}$ while systolic blood pressure increased after noise exposure, but no significant differences between values before and after exposure were found.

In the current study the total and free testosterone levels were significantly lower among workers exposed to noise level above $85 \mathrm{~dB}$.The levels of serum total and free testosterone levels were lower in 15 workers (28.8\%) of group A for both parameters compared to group $\mathrm{B}$ who were completely normal and the differences were statistically significant $(\mathrm{p}<0.05)$ as shown in (Table 3$)$.

Dzhambov (2016) reported in his study on chronic noise exposure and testosterone deficiency that exposure to loud noise was associated with lower TT, but the effect was statistically significant only among those aged $\geq 37$ years. Also, study done by Chamkoori et al. (2015) on the effect of noise stress on the hormonal and semen analysis parameters in industrial workers of Bushehr, Iran showed a significant decrease in concentration of testosterone, LH and FSH and major changes in sperm parameters among workers exposed to noise from $85 \mathrm{dBA}$ to $119 \mathrm{dBA}$. 
The present study results showed that there was a statistically significant positive correlation between duration of noise exposure for years and both of systolic and diastolic blood pressure measurements and level of serum total cholesterol as shown in (Table 4).

The study results were supported by those of Lee et al. (2009), who focused in their cohort study on the effect of chronic noise exposure on blood pressure among male workers at a metal manufacturing industry and they concluded that chronic noise exposure increases systolic blood pressure.

The findings of the current work also showed that there was a statistically significant positive correlation between duration of noise exposure for years and the level of serum total cholesterol as shown in (Table 4).

This was in accordance with those detected by Suadicani et al. (2012), in their study on occupational noise exposure, social class, and risk of ischemic heart disease in the Copenhagen male who found that the lipid fractions and body mass index (BMI) were very high after prolonged periods of noise exposure.

These results were in agreement with those reported by Hamzehet al. (2016), who performed a case-control study among workers of insulator manufacturing plants and found that long-term exposure to noise can lead to increased level of cholesterol among workers which was statistically significant and subsequently lead to increased risk of cardiovascular disease.

The present study results also showed that there was a statistically significant negative correlation between duration of noise exposure for years and the level of serum total and free testosterone as shown in table 4.

These was in accordance with those of Ogale (1999) who found that prolonged exposure to $100 \mathrm{~dB}$ noise had permanent effects on testicular histology and morphology, and results in changes in serum levels of testosterone.

These results were also in agreement with those of Chamkori et al. (2015), who studied the effect of chronic exposure to loud workplace noise generated from electric saws for 8 hours daily for 40 hours weekly. They found that the levels of $\mathrm{FSH}, \mathrm{LH}$, and testosterone were reduced at noise intensity of $119 \mathrm{~dB}$.

Using logistic regression analysis in the present study revealed that noise is a significant independent predictor for the presence of high serum total cholesterol level and lower free and 
total testosterone levels; it is also a significant predictor for the presence of hearing impairment and attacks of sleep apnea (Table 5).

Similar to the findings of the present study, a study reported that the total cholesterol ratio also ranked highly for the long-term signal-to-noise ratios (Paul et al., 2014)

Researchers reported that occupational exposure to noise was a major physical stressor and a risk factor affecting physical and psychological outcomes such as hearing impairment, cardiovascular malfunctions, sleep disorders, and mental health; It was also negatively associated with sleeping quality (Mahendra Prashanth and Sridhar, 2008).

Gitanjali and Dhamodharan (2004) reported that a statistically significant proportion of workers exposed to loud occupational noise exhibit poor sleep quality.

\section{Conclusion : Chronic exposure to} occupational noise above intensity level $85 \mathrm{~dB}$ has many adverse health effects on exposed workers. Besides auditory effects as hearing impairment, it causes extra-auditory health effects. Hypercholesterolemia associated with prolonged exposure to noise might lead to cardiovascular serious extra-auditory effects as hypertension and ischemic heart diseases. Prolonged exposure to high noise levels will also result in lower levels of serum testosterone hormone that might cause reproductive and cardiovascular adverse health effects.

\section{Recommendations : The NIOSH} Recommended Exposure Limit (REL) for occupational noise exposure as 85 decibel, as an 8-hour time-weighted average ( $85 \mathrm{~dB}$ as an 8-hr TWA).Strict precautions should be implemented for elimination of the source of hazardous noise and substitution of the noisy equipment by quieter ones. Hearing protection devices such as earplugs or earmuffs should be available to all workers exposed to noise. The eight major components of a hearing loss prevention program described in the NIOSH guidelines should be implemented: (1) noise exposure monitoring, (2) engineering and administrative controls, (3) audiometric evaluation, (4) use of hearing protection devices, (5) education and motivation, (6) record keeping, (7) program evaluation, and (8) hearing loss prevention program audit. 


\section{Financial support}

None

\section{Conflict of interest}

There is no conflict of interest.

\section{References}

1. American Academy of Sleep Medicine (2005): International classification of sleep disorders. Diagnostic and Coding Manual. 2nd Edition. Westchester, IL.

2. American Conference of Governmental Industrial Hygienists (ACGIH) (2006b): Threshold Limit Values for chemical substances and physical agents and biological exposure indices (BEIs): Noise.

3. Babisch W (2011): Cardiovascular effects of noise. Encyclopedia of Environmental Health. Burlington: Elsevier; 532-42.

4. Basner M, Babisch W, Davis A, Brink M, Clark C, et al. (2014): Auditory and nonauditory effects of noise on health. Lancet; 383:1325-32.

5. Bhumika N, Prabhu G, Ferreira A and Kulkarni M (2013): Noise-induced hearing loss still a problem in shipbuilders: a crosssectional study in Goa, India. Ann Med Health Sci Res; 3(1):1-6.

6. Bonet-Porqueras R, Moline-Pallareas A and Olona-Cabases M (2009): The night shift: a risk factor for health and quality of life in nursing staff. Enferm Clin ; 19:76-82.
7. Chamkori A, Shariati M, Moshtaghi D and FarzadiniaP (2015): Effect of noise stress on the hormonal and semen analysis parameters in industrial workers of Bushehr, Iran. CJMB; 3(2):45-50.

8. Chan YH (2003a): Biostatistics102: Quantitative Data - Parametric \& Nonparametric Tests. Singapore Med J; 44(8): 391-6.

9. Chan YH (2003b): Biostatistics 103: Qualitative Data -Tests of Independence. Singapore Med J; 44(10): 498-503.

10. Chan YH (2003c): Biostatistics 104: Correlational Analysis. Singapore Med J; 44(12): 614-19.

11. Chan YH (2004): Biostatistics 202: logistic Regression Analysis. Singapore Med J; 45 (4): 149-53.

12. Davies H and van Kamp IV (2012): Noise and cardiovascular disease: a review of the literature 2008-2011. Noise Health; 14: 287-91.

13. Dzhambov A and Dimitrova D (2015): Chronic noise exposure and testosterone deficiency -- meta-analysis and metaregression of experimental studies in rodents. Endokrynol Pol; 66:39-46.

14. Dzhambov AM (2016): Workplace noise exposure and serum testosterone in men enrolled in the 1999-2004: National Survey .Arh Hig Rada Toksikol; 67:247-58. 
15. Gan WQ, Davies HW and Demers PA (2011): Exposure to occupational noise and cardiovascular disease in the United States: the National Health and Nutrition Examination Survey 1999-2004. Occup Environ Med; 68:183-90.

16. Gitanjali and Dhamodharan R (2004): Effect of Occupational noise on the nocturnal sleep architecture of healthy subjects. Indian J Physiol Pharmacol; 48 (1): 65-72.

17. Gopinath B, Thiagalingam A, Teber E and Mitchell P (2011): Exposure to workplace noise and the risk of cardiovascular disease events and mortality among older adults. Prev Med; 53:390-4.

18. Hamzeh M, IrajA, Saman R, Reza P, Mohammad BA et al. (2016): The Effect of Occupational Noise Exposure on Blood and Biochemical Parameters: A Case Study of an Insulator Manufacturer in Iran. Electron Physician; 8(1): 1740-6.

19. Kerns E, Masterson EA, Themann CL and Calvert GM (2018): Cardiovascular conditions, hearing difficulty, and occupational noise exposure within US industries and occupations. Am J Ind Med; 61(6):477-91.doi: 10.1002/ajim.22833.

\section{Lee JH, Kang W, Yaang SR, Choy N} and Lee CR (2009): Cohort study for the effect of chronic noise exposure on blood pressure among male workers in Busan, Korea. Am J Ind Med; 52(6):509-17.
21. Lusk SL, Gillespie B, Hagerty BM and Ziemba RA (2004): Acute effects of noise on blood pressure and heart rate. Arch Environ Health; 59: 392-9.

22. Mahendra Prashanth KV and Sridhar V (2008): The relationship between noise frequency components and physical, physiological and psychological effects of industrial workers. Noise Health; 10:90-8.

23. Mehmet GD and Sedat A (2018): The Effect of the Cholesterol Levels on Noise-Induced Hearing Loss. Int Arch Otorhinolaryngol; 22(1): 19-22.

24. Nada E, Ebraheem WM and Sheta S (2014): Noise-induced hearing loss among workers in textile factory. Egypt J Otolaryngol; 30:243-8.

25. National Institute for Occupational Safety and Health (NIOSH) (1998): (NIOSH) criteria for recommended standards: occupational exposure to noise. Cincinnati, OH: U.S Department of Health, Education and Welfare, public health service, CDC, National Institute of Safety and Health, publication No: 98126.

26. National Institute for Occupational Safety and Health (NIOSH) (2018): High blood pressure and high cholesterol associated with noisy jobs. (CDC) and Prevention, National Institute of Safety and Health (NIOSH), Vol. 4, No 6. Available at: www.cdc.gov/media/releases/2018/p0321noisy-jobs.html 
27. Ogale SB (1999): Noise overload. Public Health Nutr; 85- 9.

28. Paul PG, Les I, Adrienne CK, Andrew MT and Simes RJ (2014): Which lipid measurement should we monitor? An analysis of the lipid study.BMJ Open; 4(2): e003512.

29. Rabinowitz P and Rees T (2005): Occupational hearing loss. Textbook of Clinical Occupational and Environmental Medicine (2nd ed.,:426-362). Philadelphia: Elsevier Saunders.

30. Saba k, Ali D, Mir Saeed Y, Leila O and Mitra R (2015): The effects of occupational noise on blood pressure and heart rate of workers in an automotive parts industry. Arya Atheroscler ; 11(4): 215-9.

31. Seftel A (2006): Male hypogonadism. Part II: etiology, pathophysiology, and diagnosis. Int J Impot Res; 18:223- 8.

32. Stokholm ZA, Bonde JP, Christensen KL, Hansen ÅM and Kolstad HA (2013): Occupational Noise Exposure and the Risk of Stroke. Stroke; 44:3214-16.

33. Suadicani P, Hein $\mathrm{HO}$ and Gyntelberg $\mathrm{F}$ (2012): Occupational noise exposure and risk of ischemic heart disease, all-cause mortality - a 16-year follow-up in the Copenhagen Male Study. Scand J Work Env Hea; 38:19-26.

34. Tarter SK and Robins TG (1990): Chronic noise exposure, high-frequency hearing loss, and hypertension among automotive assembly workers. J Occup Med; 32(8):685-9.

35. Test T, Canfi A, Eyal A, Ilana SV, Einat $K$,et al. (2011): The Influence of Hearing Impairment on Sleep Quality Among Workers Exposed to Harmful Noise. Sleep; 34(1): 25-30.

36. Tomei G, Fioravanti M, Cerratti D, Sancini A, Tomao E, et al. (2010): Occupational exposure to noise and the cardiovascular system: A meta-analysis. Sci Total Environ; 408:681-9.

37. Van Kempen EE, Kruize H, Boshuizen $\mathrm{HC}$, Ameling CB, Staatsen BA, et al. (2002): The association between noise exposure and blood pressure and ischemic heart disease: A meta-analysis. Environ Health Perspect ;110: 307-17.

38. Won JU, Hong OS and Hwang WJ (2013): Actual cardiovascular disease risk and related factors. A cross-sectional study of Korean blue collar workers employed by small businesses. Workplace Health Safety; 61:163- 71 .

39. World Health Organization (WHO) (2004): Protection of the Human Environment, Occupational Noise: assessing the burden of disease from work-related hearing impairment at national and local levels, World Health Organization, Geneva (WHO Environmental Burden of Disease Series, No. 9). 